\title{
REVIEW ARTICLE OPEN \\ Content and quality of websites supporting self-management of chronic breathlessness in advanced illness: a systematic
} review

\author{
Tim Luckett ${ }^{1}$, Rebecca Disler ${ }^{1}$, Annmarie Hosie ${ }^{1}$, Miriam Johnson ${ }^{2}$, Patricia Davidson ${ }^{1,3}$, David Currow ${ }^{4}$, Anthony Sumah ${ }^{1}$ and \\ Jane Phillips ${ }^{1}$
}

\begin{abstract}
Chronic breathlessness is a common, burdensome and distressing symptom in many advanced chronic illnesses. Self-management strategies are essential to optimise treatment, daily functioning and emotional coping. People with chronic illness commonly search the internet for advice on self-management. A review was undertaken in June 2015 to describe the content and quality of online advice on breathlessness self-management, to highlight under-served areas and to identify any unsafe content. Google was searched from Sydney, Australia, using the five most common search terms for breathlessness identified by Google Trends. We also hand-searched the websites of national associations. Websites were included if they were freely available in English and provided practical advice on self-management. Website quality was assessed using the American Medical Association Benchmarks. Readability was assessed using the Flesch-Kincaid grades, with grade 8 considered the maximum acceptable for enabling access. Ninety-one web pages from 44 websites met the inclusion criteria, including 14 national association websites not returned by Google searches. Most websites were generated in the USA $(n=28,64 \%)$ and focused on breathing techniques $(n=38,86 \%)$ and chronic obstructive pulmonary disease $(n=27,61 \%)$. No websites were found to offer unsafe advice. Adherence to quality benchmarks ranged from $9 \%$ for disclosure to $77 \%$ for currency. Fifteen (54\%) of 28 written websites required grade $\geqslant 9$ reading level. Future development should focus on advice and tools to support goal setting, problem solving and monitoring of breathlessness. National associations are encouraged to improve website visibility and comply with standards for quality and readability.
\end{abstract}

npj Primary Care Respiratory Medicine (2016) 26, 16025; doi:10.1038/npjpcrm.2016.25; published online 26 May 2016

\section{INTRODUCTION}

Chronic breathlessness is a common, burdensome and distressing symptom in people with advanced chronic illness, including chronic obstructive pulmonary disease (COPD), heart failure, cancer (especially lung) and neurological diseases. ${ }^{1}$ The experience of breathlessness is individual and multidimensional, involving 'sensory-perceptual', 'affective' and 'impact' components. $^{2}$ Breathlessness may have a range of interacting causes, ${ }^{3}$ as well as complex relationships with other symptoms, notably anxiety and fatigue. ${ }^{4}$ It is an independent predictor of mortality ${ }^{5}$ and associated with negative impacts on activities of daily living and quality of life. ${ }^{6}$ Many people with chronic breathlessness periodically experience acute-on-chronic symptoms, sometimes termed breathlessness crises, ${ }^{7}$ which often lead to emergency presentations..$^{8-10}$

Management of chronic breathlessness focuses on optimising treatment for underlying pathologies, managing reversible causes, reducing the frequency and severity of crises and minimising adverse impacts on quality of life. ${ }^{3}$ Self-management is essential for implementing pharmacological and non-pharmacological treatments and sustaining everyday functioning and emotional coping. ${ }^{11}$ Self-management interventions have been defined as those 'focused on increasing a patient's knowledge and understanding of actions they can take to manage breathlessness, including education plus strategies to improve coping skills or reduce anxiety or depression, cognitive behavioural/behavioural or psycho-educational interventions; psychosocial interventions; problem-solving interventions with or without goal setting and action plans; stress management; symptom coaching and breathing techniques ${ }^{\prime 2}$ (pp 3-4).

Ideally, self-management involves patients working in collaboration with health professionals to ensure that strategies are evidence-based and optimally implemented. ${ }^{13}$ However, with the advent of the World Wide Web, patients now often search online for resources to support self-management, especially if they have limited access to services. ${ }^{14}$ Internet-based health information has the potential to influence patient behaviour and relations with health professionals in both positive and negative ways, ${ }^{15}$ giving rise to substantial research aimed at appraising and improving quality. ${ }^{16,17}$ However, no research to date has reviewed the quality of websites for self-management of chronic breathlessness. The current study set out to address this gap with the aims of (1) describing the content and quality of websites concerned with self-management of chronic breathlessness; (2) highlighting under-served areas to inform future content development; and (3) identifying any websites posing safety concerns.

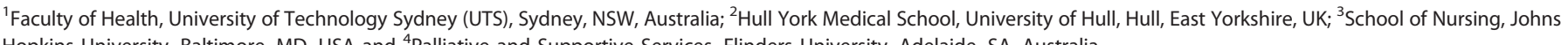
Hopkins University, Baltimore, MD, USA and ${ }^{4}$ Palliative and Supportive Services, Flinders University, Adelaide, SA, Australia.

Correspondence: T Luckett (tim.luckett@uts.edu.au)

Received 22 December 2015; revised 8 March 2016; accepted 5 April 2016 


\section{RESULTS}

Inclusion

One hundred and sixty seven web pages returned by Google searches were reviewed against inclusion criteria (see Table 1), leading to inclusion of 53 web pages.

Sixteen videos were included from YouTube searches, and another 22 web pages from the websites of the Asthma Foundation New Zealand $(n=1)$, American Lung Association $(n=3)$, American Thoracic Society (ATS; $n=3)$, Chest, Heart and Stroke Scotland $(n=9)$, Canadian Lung Association $(n=4)$ and Canadian Thoracic Society $(n=2)$ that were not identified by Google or YouTube searches. This resulted in overall inclusion of 91 web pages from 44 websites. Table 2 summarises characteristics relating to country of origin, authorship, format, target audiences and focal health conditions across these 44 websites.

\section{Quality appraisal}

When reviewed against the American Medical Association (AMA) Benchmarks, $^{18} 24$ (54\%) web pages were found to give no information on authorship, 34 (77\%) failed to attribute the advice they offered and $10(23 \%)$ gave no dates of authorship of review. Thirty-nine (89\%) websites provided only limited information on disclosure, and 4 (9\%) offered no information at all. Among 28 websites with written content, reading grade ranged from 5 to 16 (median grade 9), with 15 (54\%) failing to meet recommendations to keep reading level at grade $\leqslant 8 .{ }^{19}$

\section{Synthesis}

When coded for content using the taxonomy of Howell et al. ${ }^{12}$ $3(7 \%)$ websites were found to include content on structured education, 38 (86\%) websites included breathing techniques, 11 (25\%) included cognitive symptom management, 15 (34\%) included action planning, 1 (2\%) website included problem solving, $23(52 \%)$ included the use of support services and 10 (23\%) websites included partnership with healthcare providers; 17 (39\%) websites were considered to contain a strong selfefficacy component. No websites offered advice on goal setting. Coding content against ATS guidance ${ }^{7}$ identified that 17 (39\%) websites provided advice on managing breathlessness crises, 3 (7\%) on monitoring of breathlessness and 20 (45\%) on using pharmacological and/or non-pharmacological treatments. Additional content not included in either taxonomy referred to lifestyle factors (e.g., diet, physical activity) ( $n=27,61 \%)$, environmental factors (e.g., pollen, pollution, temperature) $(19,43 \%)$ and end-of-life considerations (3, 7\%). Supplementary Table S1 provides a breakdown of the content and focal health condition(s) of each individual website.

No websites were identified as offering unsafe advice. A consumer-developed YouTube video on using common dietary ingredients to manage breathlessness that lacked evidence for

Table 1. Numbers of web pages searched via the Google search engine in June 2015

\begin{tabular}{|lcc|}
\hline Term & \multicolumn{2}{c}{ Search results } \\
\cline { 2 - 3 } & Results (millions) & Results hand-searched \\
\hline Breathless & 19.5 & 10 \\
Shortness of breath & 10.6 & 77 \\
Dyspnoea & 3.4 & 40 \\
Wheeze & 0.72 & 30 \\
Difficulty breathing & 52 & 10 \\
\hline
\end{tabular}

effectiveness was removed from the internet shortly after being identified.

\section{DISCUSSION}

Breathlessness self-management websites identified by this review were most commonly generated in the USA and focused predominantly on COPD and breathing techniques. No websites were found that offered support for goal setting, suggesting that this may be an under-served area, despite acknowledgement that this is an essential component of self-management across chronic health conditions. ${ }^{13}$

The authors of websites rarely explained their purposes explicitly, and the majority allocated self-management limited word-space amidst more dominant content on health conditions, diagnosis and treatment. This resulted in many websites being framed from a disease-focused biomedical perspective rather than a person-centred perspective focused on ameliorating the impacts of breathlessness on daily life. Only one website included interactive features enabling content to be tailored to consumer needs and problem solving, ${ }^{20}$ highlighting a further area in need of content development. In the absence of goal-setting content, advice on action planning was limited to management of breathlessness crises, preventing exacerbations, going home from hospital and preparing to go on holiday. Advice on breathlessness monitoring occurred rarely, despite this being essential for assessing whether goals have been met and recognising changes in the severity and quality of breathlessness over time to inform decisions about when to seek medical attention. ${ }^{7}$ Website advice on when to go to Emergency typically recommended going

Table 2. Characteristics of 44 websites identified as providing support for self-management of chronic breathlessness

\begin{tabular}{lc}
\hline Characteristic & Number (\%) \\
\hline Country & \\
USA & $28(64)$ \\
UK & $5(11)$ \\
Canada & $6(14)$ \\
Australia & $3(7)$ \\
New Zealand & $1(2)$ \\
Europe & $1(2)$ \\
& \\
Author & \\
National Health Organisation & $16(36)$ \\
Other health & $20(45)$ \\
Health professional & $6(14)$ \\
User & $3(7)$ \\
& \\
Format & \\
Written Information & $23(52)$ \\
Video & $16(36)$ \\
Both & $5(11)$ \\
& \\
Target audience & \\
People with breathlessness & $45(100)$ \\
Family/carers & $8(18)$ \\
Health professionals & $4(9)$ \\
& \\
Health condition a & \\
COPD & $27(61)$ \\
Cancer & $9(20)$ \\
Heart failure & $3(7)$ \\
Unspecified & $15(34)$ \\
\hline Abbreviation: COPD, chronic obstructive pulmonary disease. \\
aSome websites included contents for more than one audience and health \\
condition. \\
\end{tabular}


immediately rather than suggesting incremental strategies of the kind recommended by the ATS. The need to better support people in self-managing crises is highlighted by recent research, suggesting that up to half of visits to Emergency Departments due to breathlessness may be potentially avoidable. ${ }^{21,22}$

A further direction for content development is identified by our finding that few websites contained information targeted at carers, despite this group's unmet needs for information and support. ${ }^{23}$ Website content for carers was concerned with understanding the carer role, as well as self-care and support networks for managing physical and emotional burden. Most practical advice to carers and patients on using treatments was focused on home oxygen, with medication-related content usually limited to mechanisms of action and adverse effects. There was little information about adjusting to increasing breathlessness and frailty and deterioration in function, advance care planning and associated changes in the carer role. Few websites broached the subject of increasing breathlessness towards the end-of-life and related care needs. ${ }^{24}$

Compliance with AMA benchmarks for quality was found to be disappointingly low despite, long-standing attempts to promote standards of online health information. ${ }^{25}$ Our finding that more than half of the websites with written content were above reading grade 8 is of special concern given that COPD and chronic heart failure are associated with cognitive impairment ${ }^{26}$ and people may seek information at times of crisis when ease of understanding is paramount. National associations are encouraged to improve accessibility of their website content with advice and review by consumers.

Limitations of the current review concern the fact that it is unlikely to offer an exhaustive account of all relevant websites and is focused on a specified time point, which quickly becomes outdated. However, the fact that we used the most widely used search engine and terms instils confidence that we identified websites accessed by the majority of consumers. It is therefore of concern that searches did not identify many of the websites developed by national associations or authorised clinical service websites. On the other hand, given the poor visibility of authoritative websites, it is encouraging that no websites were found that offered unsafe advice or sought to gain financially by means of inaccurate information, as has been found for other health-related information. ${ }^{27}$

\section{CONCLUSIONS}

Websites supporting self-management of breathlessness identified by this review were predominantly generated from the USA and focused on breathing techniques and COPD. More content is needed to support goal setting, action planning, problem solving and monitoring of breathlessness, as these are integral components of self-management in chronic illness. More websites are also needed that deal with worsening breathlessness and decline in function as illness progresses towards end-of-life and the associated information and support needs of carers. Interactive tools that can be tailored to consumer needs are especially encouraged. National associations are recommended to improve the visibility of their resources, as well as comply with standards for quality and readability of internet health information.

\section{MATERIALS AND METHODS}

A review of websites for breathlessness self-management was conducted in June 2015 from Sydney, Australia.

\section{Search and selection}

Search methods were intended to identify websites being accessed by the majority of English-speaking consumers. We searched the most widely used search engine, Google, which at the time accounted for $93 \%$ of mobile/tablet searches and $68 \%$ of desktop searches (with a further $11 \%$ being conducted via the Chinese-language engine Baidu). ${ }^{28}$ Because we expected self-management websites to include content in video format, we also searched www.YouTube.com, which enables any internet user to upload content directly and also houses much of the video content accessible from other websites.

Google and YouTube were searched using terms identified by Google Trends $^{29}$ as the five most common search terms for breathlessness: 'breathless', 'shortness of breath', 'dyspnoea', 'wheeze' and 'difficulty breathing'. We also searched websites belonging to respiratory-related national associations in Englishspeaking members of the Organisation for Economic Co-operation and Development. These included websites of the American Association for Respiratory Care, American Lung Association, ATS, Australian Lung Foundation, British Lung Foundation, British Thoracic Society, Canadian Lung Association, Canadian Thoracic Society, Chest, Heart and Stroke Scotland, Irish Lung Foundation and Thoracic Society of Australia and New Zealand. In addition, we searched the website of the Asthma Foundation New Zealand, because we knew that it contained advice on chronic breathlessness from a range of causes, as well as asthma.

Google results consist of individual web pages rather than websites, which are defined as connected groups of web pages regarded as a single entity and maintained by a single person or organisation. ${ }^{30}$ Each web page returned by the search was opened and appraised against eligibility criteria until 10 consecutive web pages failed to yield any new web pages to include. Links from web pages were followed wherever they looked likely to be relevant for self-managing breathlessness. YouTube was harder to search systematically because results are displayed in a scrolling list with related videos appearing in the right-hand margin. To most closely approximate to a consumer's search style, we searched YouTube using each term for $1 \mathrm{~h}$, clicking on video links wherever these seemed most relevant to self-management and pursuing further links as appropriate rather than returning to the original list.

\section{Eligibility criteria}

To be included, websites needed to be freely available in English and offer support for self-management of chronic breathlessness. Websites had to go beyond information about breathlessness and its causes or medical treatments to provide practical advice, tools or demonstrations that could be used to support selfmanagement by people with breathlessness and/or their carers. Provided content met these criteria, we also included websites designed for healthcare professionals on the basis that consumers may access these as well. Websites that referred to breathlessness without specifying acute or chronic were included, but websites that referred exclusively to asthma 'acute' breathlessness outside the context of chronic breathlessness were not.

\section{Data extraction}

Using an electronic proforma, information was extracted on URL, organisation, country of origin, focal health condition(s), target audience (consumer/carer/professional) and variables for quality rating (see below).

\section{Quality appraisal}

Quality appraisal of each website was undertaken by one reviewer, with random checks performed on $10 \%$ by a second reviewer. The quality of websites was evaluated using a widely used tool for this purpose, ${ }^{31}$ the AMA benchmarks. ${ }^{18}$ AMA benchmarks are concerned with whether websites provide basic information on authorship (including credentials and affiliations), attribution 
Table 3. Classification of breathlessness self-management interventions using evidence-based recommendations

Types of breathlessness self-management programmes shown to be effective by research ${ }^{11} \quad$ ATS guidance on support for dyspnoea crisis ${ }^{27}$

Structured education Information about breathlessness and its management including the actions patients can take: breathing and coughing techniques; energy conservation; health lifestyle behaviour change to increase activity/exercise; smoking cessation; management of roles and relationships; strategies for coping.

Breathing techniques skill training

Cognitive symptom management skill training

Coping training for symptoms, emotions and stress: therapeutic support; relaxation therapy.

Goal setting and action planning

Using a short-term plan of action for exacerbations or panic breathing episodes and to reach goals.

Problem-solving skills

Solution implementation and evaluation/monitoring of results; key messages and support for decision-making; skills of self-tailoring to facilitate adapting lifestyle to accommodate symptoms and to adopt health lifestyle change such as exercise: with or without surveillance; adherence measure.

Coaching in use of support Awareness of resources and navigating skills to gain services access.

Partnership with healthcare Ways to communicate effectively with providers. providers

Enhancement of self-efficacy

Teaching for performance mastery, modelling, re-interpretation of symptoms and social persuasion (peer support/modelling).
Breathing retraining including pursed lip breathing, slowed pattern of breathing, prolonged exhalation and posture modification.

Relaxation techniques, mindfulness meditation, guided imagery and distraction strategies (e.g., music, TV, reading by self or caregiver)

Use of a written action plan that includes appropriate administration and dosing of medications and stepwise titration regimens

Other

- Basic facts about causes and triggers of dyspnoea crises.

- How to identify signs and symptoms that are an indication of a dyspnoea crisis.

- How to recognise and measure changes from baseline for both intensity of dyspnoea and an affective component (anxiety or distress).

- Appropriate and individualised use of oxygen, ventilation and/or fans. (including references where applicable), currency (the dates content was added/reviewed) and disclosure of website ownership/sponsorship and potential conflicts of interest. We abandoned efforts to assess the quality of self-management content after tools designed for assessing information about health interventions were found to be a poor fit. ${ }^{32,33}$

Readability of written content was assessed using the most common approach ${ }^{25}$ - the Flesch-Kincaid Grade Level Index. ${ }^{34}$ We followed previous recommendations that grade 8 should be considered the highest level acceptable for health information to be regarded as accessible by the general public. ${ }^{19}$

\section{Synthesis}

Each website was classified according to the taxonomy shown in Table 3 by one reviewer, with random checks performed on $10 \%$ by a second reviewer. This taxonomy was developed for a Cochrane review by Howell et al. ${ }^{12}$ and includes self-management strategies found to be effective by previous research. ${ }^{12}$ To enable description of content related to breathlessness crises, this taxonomy was supplemented by recommendations for patient education on this topic provided by the ATS. ${ }^{7}$ Judgments regarding risks to safety were based on a review of related literature and the group's clinical expertise.

\section{ACKNOWLEDGEMENTS}

We acknowledge the Faculty of Health at the University of Technology Sydney for funding this work.

\section{CONTRIBUTIONS}

All authors contributed to authorship of the manuscript.

\section{COMPETING INTERESTS}

The authors declare no conflict of interest.

\section{FUNDING}

Internal grant from the Faculty of Health at the University of Technology Sydney. 


\section{REFERENCES}

1. Booth, S. \& Dudgeon, D. Dyspnoea in Advanced Disease: a Guide to Clinical Management (Oxford University Press, 2006).

2. Parshall, M. B. et al. An official American Thoracic Society statement: update on the mechanisms, assessment, and management of dyspnea. Am. J. Respir. Crit. Care Med. 185, 435-452 (2012).

3. Currow, D. C., Higginson, I. J. \& Johnson, M. J. Breathlessness--current and emerging mechanisms, measurement and management: a discussion from an European Association of Palliative Care workshop. Palliat Med. 27, 932-938 (2013)

4. Chan, C. W. H., Richardson, A. \& Richardson, J. A study to assess the existence of the symptom cluster of breathlessness, fatigue and anxiety in patients with advanced lung cancer. Eur. J. Oncol. Nurs. 9, 325-333 (2005).

5. Figarska, S. M., Boezen, H. M. \& Vonk, J. M. Dyspnea severity, changes in dyspnea status and mortality in the general population: the Vlagtwedde/Vlaardingen study. Eur. J. Epidemiol. 27, 867-876 (2012).

6. McMillan, S. C. \& Small, B. J. Symptom distress and quality of life in patients with cancer newly admitted to hospice home care. Oncol. Nurs. Forum 29, 1421-1428 (2002).

7. Mularski, R. A. et al. An official American Thoracic Society workshop report: assessment and palliative management of dyspnea crisis. Ann. Am. Thor. Soc. 10, S98-106 (2013).

8. Wallace, E. M., Cooney, M. C., Walsh, J., Conroy, M. \& Twomey, F. Why do palliative care patients present to the emergency department? Avoidable or unavoidable? Am. J. Hosp. Palliat. Med. 30, 253-256 (2013)

9. Hjermstad, M. J. et al. Are emergency admissions in palliative cancer care always necessary? Results from a descriptive study. BMJ Open. 3, e002515 (2013).

10. Davidson, P. M. \& Currow, D. C. Management of refractory dyspnoea evidencebased interventions. Cancer Forum 34, 86-90 (2010).

11. Lorig, K. R. \& Holman, H. Self-management education: history, definition, outcomes, and mechanisms. Ann. Behav. Med. 26, 1-7 (2003).

12. Howell, D. M. et al. Self management interventions for breathlessness in adult cancer patients (Protocol). Cochrane Library, http://www.cochrane.org/CD009623/ SYMPT_self-management-interventions-for-breathlessness-in-adult-cancerpatients (2012).

13. Bodenheimer, T., Lorig, K., Holman, H. \& Grumbach, K. Patient self-management of chronic disease in primary care. JAMA 288, 2469-2475 (2002).

14. Amante, D. J., Hogan, T. P., Pagoto, S. L., English, T. M. \& Lapane, K. L. Access to care and use of the Internet to search for health information: results from the US National Health Interview Survey. J. Med. Internet Res. 17, e106 (2015)

15. McMullan, M. Patients using the Internet to obtain health information: how this affects the patient-health professional relationship. Patient Educ. Couns. 63, 24-28 (2006)

16. Powell, J. A., Lowe, P., Griffiths, F. E. \& Thorogood, M. A critical analysis of the literature on the Internet and consumer health information. J. Telemed. Telecare. 11(Suppl 1): 41-43 (2005).

17. Lee, K., Hoti, K., Hughes, J. D. \& Emmerton, L. M. Interventions to assist health consumers to find reliable online health information: a comprehensive review. PLOS ONE 9, e94186 (2014).

18. Silberg, W. M., Lundberg, G. D. \& Musacchio, R. A. Assessing, controlling, and assuring the quality of medical information on the Internet: Caveant lector et viewor--Let the reader and viewer beware. JAMA 277, 1244-1245 (1997).
19. SA Health. Health Literacy [Internet]. State Government of South Australia: Adelaide, SA, Australia, (2013).

20. Chest HaSS. Traffic Lights for COPD. 2014. Available at: http://www.chss.org.uk/ documents/2015/11/copd-traffic-lights-pdf.pdf. (Accessed on 11 December 2015).

21. Hutchinson, A., Pickering, A., Williams, P., Bland, M. \& Johnson, M. Emergency Department Presentations By People With Chronic Breathlessness: A Prevalence Survey (European Association for Palliative Care, 2015).

22. Wallace, E. M., Cooney, M. C., Walsh, J., Conroy, M. \& Twomey, F. Why do palliative care patients present to the emergency department? Avoidable or unavoidable? Am. J. Hosp. Palliat. Care 30, 253-256 (2013).

23. Caress, A. L., Luker, K. A., Chalmers, K. I. \& Salmon, M. P. A review of the information and support needs of family carers of patients with chronic obstructive pulmonary disease. J. Clin. Nurs. 18, 479-491 (2009).

24. Currow, D. C. et al. Do the trajectories of dyspnea differ in prevalence and intensity by diagnosis at the end of life? A consecutive cohort study. J. Pain Symptom Manage. 39, 680-690 (2010).

25. Eysenbach, G., Powell, J., Kuss, O. \& Sa, E. R. Empirical studies assessing the quality of health information for consumers on the world wide web: a systematic review. JAMA 287, 2691-2700 (2002).

26. Dodd, J. W., Getov, S. V. \& Jones, P. W. Cognitive function in COPD. Eur. Respir. J. 35, 913-922 (2010).

27. Meric, F. et al. Breast cancer on the world wide web: cross sectional survey of quality of information and popularity of websites. BMJ 324, 577-581 (2002).

28. Netmarketshare.com. Search Engine Market Share. Available at: http://www.netmarketshare.com. (Accessed on 12 June 2015).

29. Google. Google Trends. Available at: https://www.google.com.au/trends/. (Accessed on 12 June 2015).

30. Dictionary.com. Website Definition. Available at: http://dictionary.reference.com/ browse/website. (Accessed on 3 November 2015).

31. Hanif, F., Read, J. C., Goodacre, J. A., Chaudhry, A. \& Gibbs, P. The role of quality tools in assessing reliability of the internet for health information. Inform. Health Soc. Care 34, 231-243 (2009).

32. Charnock, D., Shepperd, S., Needham, G. \& Gann, R. DISCERN: an instrument for judging the quality of written consumer health information on treatment choices. J. Epidemiol. Community Health. 53, 105-111 (1999).

33. Health Summit Working Group. Information Quality Tool. 2000. Available at: http://HitiWeb.mitretek.org/iq/default.asp. (Accessed on 26 August 2015).

34. Kincaid, J. P., Fishburne, R. P., Rogers, R. L. \& Chissom, B. S. Derivation of New Readability Formulas (Automated Readability Index, Fog Count, and Flesch Reading Ease Formula) For Navy Enlisted Personnel. Research Branch Report 8-75 (Naval Technical Training, Millington, TN, USA; Naval Air Station, Memphis, TN, USA, 1975)

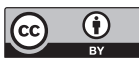

This work is licensed under a Creative Commons Attribution 4.0 International License. The images or other third party material in this article are included in the article's Creative Commons license, unless indicated otherwise in the credit line; if the material is not included under the Creative Commons license, users will need to obtain permission from the license holder to reproduce the material. To view a copy of this license, visit http://creativecommons.org/licenses/ by/4.0/

Supplementary Information accompanies the paper on the npj Primary Care Respiratory Medicine website (http://www.nature.com/npjpcrm) 